\title{
Impaired recovery in diabetic rat nerve following anoxic conduction block
}

\author{
Per Lindström ${ }^{a}$, Tom Brismar* ${ }^{\mathrm{b}}$, Anders A.F. Sima ${ }^{\mathrm{c}}$ \\ a Department of Neurology, Karolinska Hospital, S-10401 Stockholm, Sweden \\ ${ }^{b}$ Department of Clinical Neurophysiology, University Hospital, S-58185 Linköping. Sweden \\ ${ }^{\mathrm{c}}$ Department of Pathology, University of Michigan, School of Medicine, Ann Arbor, MI 48102-0602, USA
}

Received 17 January 1994; revision received 6 June 1994; accepted 9 June 1994

\begin{abstract}
It is well documented that diabetic rats and subjects have a paradoxical resistance to ischemic conduction block although the nerves of diabetics are more susceptible to entrapment neuropathies. The aim of the present study was to further analyze the effect of anoxia on the diabetic nerve. Nerve conduction was measured in vitro in desheathed sciatic nerves from spontaneously diabetic rats (BB-Wistar) and age-matched controls. After onset of anoxia the compound action potential (CAP) decreased to $50 \%$ in $17 \mathrm{~min}$ in diabetic rat nerves and $8 \mathrm{~min}$ in normals. Following reoxygenation CAP recovered to $50 \%$ in $30 \mathrm{~s}$ in normal rat nerves and after $3 \mathrm{~min}$ the recovery was $92 \%$. In nerves from diabetic animals $50 \%$ recovery took $4 \mathrm{~min}$, but still after $12 \mathrm{~min}$ CAP was suppressed to a $60 \%$ level of the original. Longer periods of anoxia did not impair the recovery in normal nerve as it did in the diabetic ones. This defective recovery after anoxia in nerves from diabetic animals may be relevant for the understanding of the pathogenesis of entrapment neuropathies in diabetic subjects.
\end{abstract}

Keywords: Diabetes mellitus; Diabetic neuropathy; Anoxia; Ischemia; Nerve conduction; BB-Wistar rat

\section{Introduction}

Patients with diabetes mellitus show a higher incidence of entrapment neuropathies than the general population [1-4] suggesting that the diabetic nerve is more susceptible to hypoxic or ischemic injury. Paradoxically though, the diabetic nerve has an increased resistance to acutely induced ischemic conduction block [5-7]. This resistance to ischemic conduction block has also been

\footnotetext{
* Corresponding author, Tel.: 46-13-222030; Fax.: 46-13224541
}

demonstrated in animals with diabetes both in vivo [8] and in isolated nerve [9]. The phenomenon occurs soon after the onset of diabetes even in the absence of clinical neuropathy $[10,11]$.

The cause of this abnormal resistance to acutely induced ischemia and anoxia in diabetes remains obscure. It is not specific for diabetes but has been described in uremia $[12,13]$ chronic liver disease [14,15] hypercalcemia [16] and motor neuron disease [17]. It is also observed in non-diabetic subjects with chronic hypoxia [18], which has led to the notion that hypoxia may be a contributing factor in the pathogenesis of diabetic neuropathy 
[19-22]. In the present study we have compared the recovery phase following anoxic conduction block in diabetic and normal rat nerves to explore further abnormalities that may be related to the pathogenesis of diabetic neuropathy.

\section{Materials and methods}

\subsection{Animals}

Eight pre-diabetic BB/W-rats were obtained from the NIH-colony at the Department of Pathology, University of Massachusetts, Worchester, MA. Prediabetic BB/W-rats were carefully monitored as to the onset of diabetes which occurred at a mean age of $82 \pm 2$ days. Diabetic rats were maintained on small daily doses $(0.5-3.0$ IU/day) of insulin protamin-zinc (ConnaughtNovo, Toronto, Ont.) as previously described in detail [23]. Diabetic rats showed a mean blood glucose value of $19.0 \pm 2.4 \mathrm{mM}$ when sacrificed $8-16$ weeks after detection of diabetes. Eight male nondiabetes prone age-matched BB/W-rats with a mean blood glucose value of $9.2 \pm 0.4 \mathrm{mM}$ served as controls.

\subsection{Recording procedure and conditions}

Animals were anesthetized with intramuscular injections of Hypnorm ${ }^{\mathrm{R}}$ (Janssen) $0.2 \mathrm{ml} / \mathrm{kg}$ body weight and intraperitoneally injected pentobarbital sodium $25 \mathrm{mg} / \mathrm{kg}$ body weight. Ten sciatic nerves were examined from diabetic rats and an equal number of non-diabetic control nerves were assessed. Approximately $40 \mathrm{~mm}$ of the sciatic nerve were excised, desheathed and placed in a thin Perspex recording chamber as previously described [24]. The chamber was placed in a slot of an aluminium block that was kept at $37^{\circ} \mathrm{C}$ by circulating water. In the recording chamber, electrodes were placed $4 \mathrm{~mm}$ apart along the nerve. The amplitude of the compound action potential (CAP) was measured following a stimulating pulse of supramaximal strength delivered at $1 \mathrm{~Hz}$. The nerve was then superfused with an oxygenated Ringer's solution containing $154 \mathrm{mM} \mathrm{NaCl}, 5.6$ $\mathrm{mM} \mathrm{KCl}, 2.0 \mathrm{mM} \mathrm{CaCl} 2$ and $10 \mathrm{mM}$ Hepes buffer titrated with $\mathrm{NaOH}$ to $\mathrm{pH}$ 7.4. After a CAP reference level $(100 \%)$ had been established during $10 \mathrm{~min}$, anoxia was initiated by superfusion with a nitrogenated Ringer's solution [24] and the recording chamber was sealed off with Perspex plugs to prevent gas exchange from the outside. The extent of CAP decline expressed in percent was measured at various time intervals up to $45 \mathrm{~min}$ after the initiation of anoxia. For the recovery experiments the nerve was again superfused with $100 \%$ oxygenated Ringer's solution and the CAP was measured at various time intervals up to 12 min following re-oxygenation.

\subsection{Statistical methods}

All values are expressed as mean \pm S.D. Comparisons between diabetic and non-diabetic rats were performed using Student's $t$-test.

\section{Results}

After the onset of anoxia, a $50 \%$ reduction in CAP occurred after $9.3 \pm 0.7 \mathrm{~min}$ in non-diabetic rats, whereas diabetic sciatic nerves required $16.1 \pm 1.8 \mathrm{~min}(P<0.001)$ (Fig. 1$)$. The data obtained from control nerves are similar to our previous findings [26]. To reach the 5\% level of the original value (near complete conduction block) required $26.7 \pm 2.6 \mathrm{~min}$ in non-diabetic sciatic nerves compared with $34.4 \pm 4.3 \mathrm{~min}$ in diabetic sciatic nerves $(P<0.001)$ (Fig. 1).

When complete anoxic block had been obtained, the nerves were again superfused with $100 \%$ oxygenated Ringer's solution and the recovery of CAP was examined. In normal nerves CAP had recovered to $50 \%$ in $0.5 \mathrm{~min}$ and after $3 \mathrm{~min}$ the recovery was $92.1 \pm 2.3 \%$ of the original CAP. In diabetic nerves $50 \%$ recovery of CAP required $4.1 \pm 1.7 \mathrm{~min}(P<0.001)$ and following $12 \mathrm{~min}$ of re-oxygenation they had only recovered to $59.7 \pm 7.8 \%$ of the original CAP.

In order to exclude the possibility that this difference in recovery between control and diabetic nerves was due to the longer exposure of diabetic nerves to anoxia, one group of control nerves $(n=5)$ was re-oxygenated immediately following total anoxic block (duration of anoxia $35 \mathrm{~min}$ ) and another $(n=5)$ was kept anoxic for an additional $15 \mathrm{~min}$. After prolonged anoxia (50 $\mathrm{min}), 50 \%$ recovery of CAP required $1.5 \pm 0.4$ min compared with $1.2 \pm 0.3 \mathrm{~min}$ in nerves exposed to anoxia for 


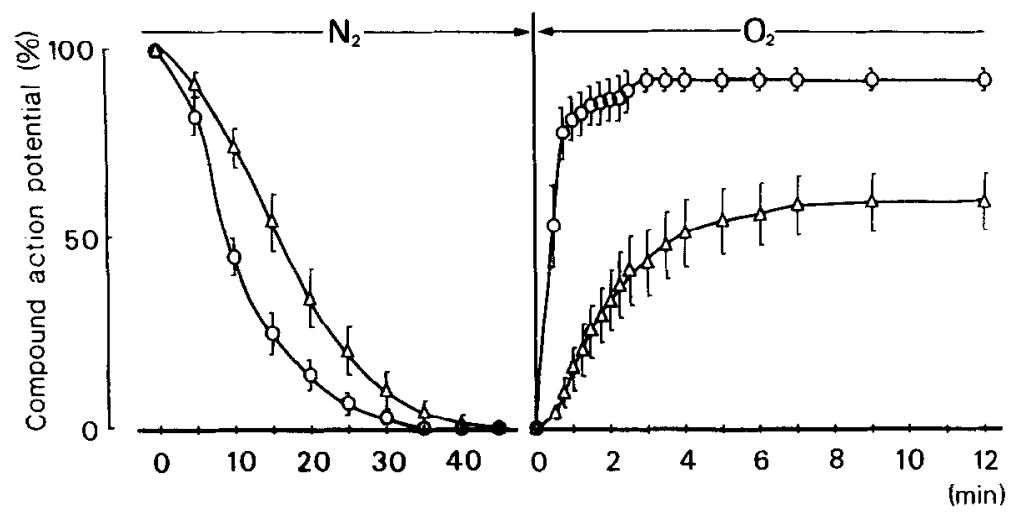

Fig. 1. Time course of anoxic block (left) and subsequent recovery (right) in sciatic nerves from non-diabetes prone (O) and diabetic ( $\triangle$ ) BB/W-rats. A reference level $(100 \%)$ of compound action potential (CAP) amplitude was established during 10 min prior to the anoxic period. Each data point represents the mean \pm S.D. of ten nerves in each group.

$35 \min (P=$ N.S. $)$. Following $4 \mathrm{~min}$ of reoxygenation the CAP recovery was above $90 \%$ (Fig. 2), indicating that the delayed and incomplete recovery in diabetic nerves under these conditions was not due to prolonged anoxic exposure.

\section{Discussion}

The present data confirm earlier reports demonstrating a resistance to ischemic conduction

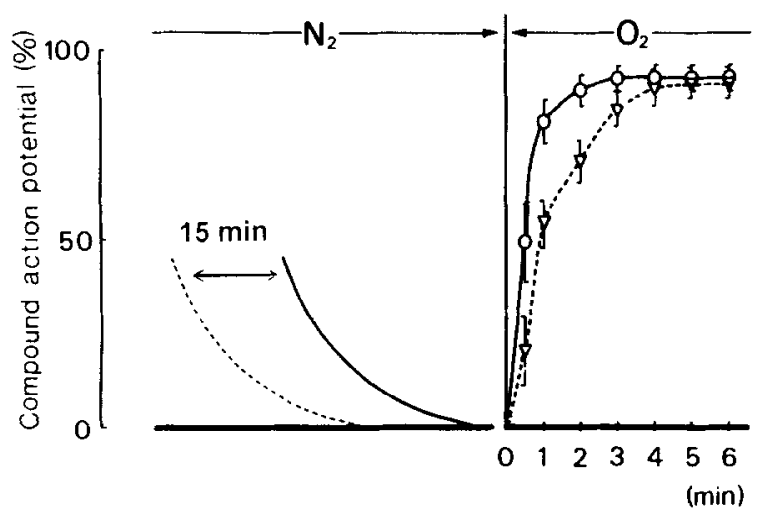

Fig. 2. Effect of anoxia duration on recovery in normal nerves. In both groups the nerves were completely blocked after a period of anoxia for $\mathbf{3 5}$ min (drawn schematically in left panel from data in Fig. 1). Five nerves were immediately perfused with $100 \%$ oxygenated Ringer's solution (solid line) and five nerves were kept anoxic for an additional $15 \mathrm{~min}$ following complete conduction block (total time of anoxia $50 \mathrm{~min}$ ), before being perfused with oxygen saturated solution (broken line, right panel). Each data point represents the mean \pm S.D. of five nerves. block in diabetic nerve [5-7]. In the diabetic $\mathrm{BB} / \mathrm{W}$-rat sciatic nerve the time required for a $50 \%$ anoxic conduction block was approximately doubled compared with non-diabetic control nerves. These findings are in agreement with the data of Seneviratne and Peiris [9], who found almost a doubling of the time required to achieve a $50 \%$ conduction block in sciatic nerves of alloxan diabetic rats, as well as those reported by Jamarillo et al. [8], who described a doubling of the time required for conduction block in the tail nerve of streptozotocin diabetic rats.

The recovery phase of the diabetic nerve following anoxic conduction block has not previously been studied. In the present study non-diabetic rats recovered $90 \%$ of the maximum CAP in $3 \mathrm{~min}$, whereas diabetic sciatic nerves recovered only $45 \%$ of the CAP in the same time and showed only a $60 \%$ recovery after $15 \mathrm{~min}$ of re-oxygenation. A delayed recovery of nerve conduction following anoxic exposure appears to be present also in diabetic subjects after cuffing of the nerve (Lindström and Brismar, unpublished data). It is therefore possible that this protacted condition block following episodes of anoxia may contribute to the high incidence of entrapment neuropathies in diabetic patients [1-3].

It has been suggested that the diabetic nerve is capable of metabolizing excess glucose via nonoxidative pathways to sustain its conductivity during hypoxic or ischemic conditions [8]. An alterna- 
tive hypothesis proposes that abnormalities in membrane permeability properties would prevent an efflux of $\mathrm{K}^{+}$thus counteracting the accumulation of extracellular $\mathrm{K}^{+}$that would otherwise cause a depolarization block [9]. Ritchie [25] has proposed that a slight depolarization of the diabetic nerve, secondary to reduced $\mathrm{Na}, \mathrm{K}$ ATPase activity, decreases the sodium current and thereby the metabolic cost of impulse transmission. However, recent studies on impulse conduction in rat tail nerves have demonstrated a reduced capacity to transmit high-frequency trains in streptozotocin diabetic rats [26]. Furthermore, measurements of the threshold for excitation in nerves of diabetic subjects did not indicate any abnormal depolarization [27] and in normal rat nerve, we have demonstrated that the anoxic conduction block was not secondary to changes in intra-axonal $\left[\mathrm{Na}^{+}\right]$or $\left[\mathrm{K}^{+}\right]$following impulse activity, nor was it correlated to inhibition of the $\mathrm{Na}, \mathrm{K}-\mathrm{ATPase}$ activity [24]. Instead, the anoxic block seemed to depend on sodium-channel inactivation as demonstrated in single voltage clamped rat fibres [28].

However, when ouabain-inhibited normal nerves are rendered anoxic, they exhibit a delay in the onset of conduction block, and the recovery after the anoxic episode is prolonged and incomplete [24]. These properties are similar to those demonstrated in peripheral nerves from the BB/Wrat in the present study. The biochemical defects that characterize the neuropathy in the diabetic rat consist of a decreased sodium permeability in the axonal membrane and a marked decrease in $\mathrm{Na}, \mathrm{K}$ ATPase activity manifested by a 5 -fold increase in intra-axonal $\left[\mathrm{Na}^{+}\right]$[29-32]. It is conceivable that in the diabetic nerve, as in normal nerves treated with ouabain, the delayed effect of anoxia is related to the decrease in $\mathrm{Na}, \mathrm{K}$-ATPase activity. Low Na,K-ATPase levels may conserve energy by decreasing ATP consumption, which would delay the onset of anoxic conduction block. The impaired recovery in the diabetic rat nerve (like the ouabain-treated nerve) may be related to the elevated intracellular sodium concentration. Thus, experiments by Stys et al. [31] on isolated rat optic nerve have indicated that anoxia causes elevated intracellular $\left[\mathrm{Ca}^{2+}\right]$, secondary to increased intra- cellular $\left[\mathrm{Na}^{+}\right]$and reversed action of a Na-Ca exchange mechanism.

In conclusion, we have found that although the diabetic rat nerve has an abnormal resistance to anoxia manifested as a prolonged time prior to conduction block in the acute experiment, there is a defective recovery after the anoxic episode which was not seen in normal nerves. If a similar defect is present in diabetic subjects it may contribute to a greater susceptibility to chronic ischemia or hypoxia which may be associated with nerve entrapment.

\section{Acknowledgements}

The present studies were supported by the Swedish and Canadian Diabetes Associations, the Swedish Medical Research Council (grant 14X4255), the Medical Research Council of Canada (grant MA-9351) and the Juvenile Diabetes Foundation International.

\section{References}

[1] Brown, M.J. and Greene, D.A. (1984) Diabetic neuropathy. In: A. Asbury, R.W. Gilliatt (Eds.), Peripheral Nerve Disorders. Butterworths, London, pp. 126-153.

[2] Gilliatt, R.W. and Willison, V. (1962) Peripheral nerve conduction in diabetic neuropathy. J. Neurol. Neurosurg. Psychiatry 25, 11-18.

[3] Mulder, D.W., Lambert, E.H., Bastron, J.A. and Sprague, R.G. (1961) The neuropathies associated with diabetes mellitus. A clinical and electromyographic study of 103 unselected patients. Neurology 11, 275-284.

[4] Thomas, P.K. and Eliasson, S.G. (1984) Diabetic neuropathy. In: P. Dyck, P.K. Thomas, E.H. Lambert and R. Bunge (Eds.), Peripheral Neuropathy. Saunders, Philadelphia, pp. 1773-1810.

[5] Horowitz, S.H. and Ginsberg-Fellner, V. (1979) Ischaemia and sensory nerve conduction in diabetes mellitus. Neurology 29, 695-704.

[6] Senevirante, K.N. and Peiris, O.A. (1968) The effect of ischaemia on the excitability of human sensory nerve. $J$. Neurol. Neurosurg. Psychiatry 31, 338-347.

[7] Steiness, I. (1959) Vibratory perception in diabetics during arrested blood flow to the limb. Acta Med. Scand. 163, 195-205.

[8] Jaramillo, J., Simard-Duqesne, N. and Dvornik, D. (1985) Resistance of the diabetic rat nerve to ischemic inactivation. Can. J. Physiol. Pharmacol. 63, 773-777.

[9] Senevirante, K.N. and Peiris, O.A. (1969) The effects of 
hypoxia on the excitability of the isolatded peripheral nerves of alloxan-diabetic rats. J. Neurol. Neurosurg. Psychiatry 33, 462-469.

[10] Kuriya, N., Mori, M. and Miyake, S. (1986) Effect of ischaemia on peripheral nerve function in diabetes mellitus. Diabetes Res. Clin. Pract. 2, 277-282.

[11] Steiness, I. (1961) Influence of diabetic status on vibratory perception during ischaemia. Acta Med. Scand. 170, 319-338.

[12] Castaigne, P., Cathala, H.-P., Bessart-Boulange, L. and Petrover, M. (1972) Effect of ischaemia on peripheral nerve function in patients with chronic renal failure undergoing dialysis treatment. J. Neurol. Neurosurg. Psychiatry 35, 631-637.

[13] Christensen, J.N. and Orskov, H. (1969) Vibratory perception during ischemia in uremic patients with mild carbohydrate intolerance. J. Neurol. Neurosurg. Psychiatry 32, 519-524.

[14] Nielsen, V.K. and Kardel, T. (1975) Delayed decrement of the nerve impulse propagation during induced limb ishaemia in chronic hepatic failure. J. Neurol. Neurosurg. Psychiatry 38, 966-976.

[15] Senevirante, K.N. and Peiris, O.A. (1970) Peripheral nerve function in chronic liver disease. J. Neurol. Neurosurg. Psychiatry 33, 609-614.

[16] Gregersen, G. and Pilgaard, S. (1971) The effect of ischaemia on vibration sense in hypo- and hypercalcemia and in demyelinated nervers. Acta Neurol. Scand. 47, 71-79.

[17] Shahani, B. and Russel, W.R. (1969) Motor neuron disease. An abnormality of nerve metabolism. J. Neurol. Neurosurg. Psychiatry 32, 1-5.

[18] Masson, E.A., Church, S.E., Woodcock, A.A., Hanley, S.P. and Boulton, A.J.M. (1988) Is resistance to ischaemic conduction failure induced by hypoxia? Diabetologia 31, 762-765.

[19] Johnson, P.C., Doll, S.C. and Cromey, D.W. (1986) Pathogenesis of diabetic neuropathy. Ann. Neurol. 19, 450-457.

[20] Low, P.A., Ward, K., Schmelzer, J.D. and Brimijoin, S. (1985) Ischaemic failure and energy metabolism in experimental diabetic neuropathy. Am. J. Physiol. 248, 457-462.

[21] Newrick, P.G., Wilson, A.J., Jakubowski, J., Boulton, A.J.M. and Ward, J.D. (1986) Sural nerve oxygen tension in diabetes. Br. Med. J. 293, 1053-1054.
[22] Tuck, R.R., Schmelzer, J.D. and Low, P.A. (1981) Endoneurial blood flow and oxygen tension in the sciatic nerves of rats with experimental diabetic neuropathy. Brain 107, 935-950.

[23] Sima, A.A.F. (1985) Can the BB-rat help to unravel diabetic neuropathy? Annot. Neuropathol. Appl. Neurobiol. 11, 253-264.

[24] Lindström, P. and Brismar, T. (1991) Mechanism of anoxic conduction block in mammalian nerve. Acta Physiol. Scand. 141, 429-433.

[25] Ritchie, J.M. (1985) A note on the mechanism of resistance to anoxia and ischaemia in pathophysiological mammalian myelinated nerve. J. Neurol. Neurosurg. Psychiatry 48, 274-277.

[26] Nielsen, J.F., Andersen, H. and Nielsen, V.K. (1993) Reduced capability of transmitting high frequency impulses in tail nerves of diabetic rats. Muscle Nerve 16, 283-288.

[27] Strupp, M., Bostock, H., Weigl, P., Piwernetz, K., Renner, R. and Grafe, P. (1990) Is resistance to ischaemia of motor axons in diabetic subjects due to membrane depolarization? J. Neurol. Sci. 99, 271-280.

[28] Brismar, T. (1981) Potential clamp analysis of the effect of anoxia on the nodal function of rat peripheral nerve fibers. Acta Physiol. Scand. 112, 495-496.

[29] Brismar, T. and Sima, A.A.F. (1981) Changes in nodal function in nerve fibres of the spontaneously diabetic BB-Wistar rat. Potential clamp analysis. Acta Physiol. Scand. 113, 499-506.

[30] Brismar, T., Sima, A.A.F. and Greene, D.A. (1987) Reversible and irreversible nodal dysfunction in diabetic neuropathy. Ann. Neurol. 21, 504-507.

[31] Das, P.K., Bray, G.M., Aguayo, A.J. and Rasminsky, M. (1976) Diminished ouabain-sensitive, sodium-potassium ATPase activity in sciatic nerves of rats with streptozotocin-induced diabetes. Exp. Neurol. 53, 285-288.

[32] Greene, D.A., Lattimer, V. and Sima, A.A.F. (1987) Sorbitol, myo-inositol and sodium potassium ATPase in the pathogenesis of diabetic complications. N. Engl. J. Med. 316, 599-606.

[33] Stys, P.K., Waxman, S.G. and Ransom, B.R. (1991) $\mathrm{Na}^{+}-\mathrm{Ca}^{2+}$ exchanger mediates $\mathrm{Ca}^{2+}$ influx during anoxia in mammalian central nervous system white matter. Ann Neurol. 30, 375-380. 